\title{
Perceptions of the affordable care act by Physician Assistants
}

\author{
Martina I. Reinhold, Theresa Bacon-Baguley \\ Physician Assistant Department, Grand Valley State University, Allendale, USA
}

Received: January 24, 2019

Accepted: March 18, 2019

Online Published: March 27, 2019

DOI: $10.5430 /$ ijh.v5n1p33

URL: https://doi.org/10.5430/ijh.v5n1p33

\begin{abstract}
Objective: Implementation of the affordable care act (ACA) resulted in an increased number of insured individuals and a shortage of primary care physicians. Physician Assistants (PAs) are poised to address this shortage since the PA profession is grounded in teamwork exemplified by the Accountable Care Organizations supported by the ACA. This study assesses the perception of the ACA by PAs providing healthcare services during implementation of the ACA.

Methods: In this repeated cross-sectional study, alumni from a Midwest PA program were surveyed in 2014, 2016 and 2018 on knowledge and perception of the ACA. Questions addressed the ACA impact on the PA profession and on patients' access to healthcare.

Results: During the initial four years of ACA implementation, the following increases in perception were seen: 1) $32 \%$ increase in positive outlook of healthcare; 2) 37\% increase in positive influence on PA practice; 3) 30\% increase in positive impact of practice autonomy; 4) $64 \%$ increase in positive impact for patients; and 5) $33 \%$ increase in patient access to care. Additionally, the inability to choose a provider increased by $18 \%$.

Conclusions: Over the last four years PAs have perceived positive effects pertaining to their practice and regarding the impact on their patients despite an increase in the inability to choose a provider. Inability to choose a provider may in part be due to the rising number of narrow-network plans. The findings of greater autonomy and increased compensation for PAs are contrary to physicians who perceive the ACA to decrease their autonomy and their compensation.
\end{abstract}

Key Words: Physician Assistants, Affordable care act, Healthcare, Primary care, PA practice, Healthcare access

\section{INTRODUCTION}

The current US health care system is in crisis. Although medical advances have led to improved care provided to patients, the cost of health care is rising much faster than anyone's ability to pay for it. Currently, the federal government spends approximately $18 \%$ of its federal budget on healthcare; a number that is predicted to reach $19.7 \%$ in $2026 .{ }^{[1]}$ The Patient Protection and affordable care act (ACA) or Obama Care passed in 2010, which resulted in a significant change to the health care system's landscape in the United States (see Figure 1). ${ }^{[2]}$ The ACAs three main goals are: increase health insurance coverage, reduce the rising healthcare cost, and improve the quality of care provided. ${ }^{[3]}$ Although recent legislation has modified some key aspects of the ACA (such as the penalty requirement if non-compliant with mandate to purchase insurance), the ACA appears to remain for the foreseeable future. ${ }^{[4]}$

The primary objectives to reach the goals of the ACA are

\footnotetext{
* Correspondence: Martina I. Reinhold, Ph.D.; Email: reinholm@gvsu.edu; Address: Grand Valley State University, 301 Michigan ST NE, Grand Rapids, MI 49503, USA.
}

Published by Sciedu Press 
to make affordable health insurance available, expand the Medicaid program, and support innovative medical care delivery methods. Making affordable health insurance available resulted in an increase of over 20 million Americans obtaining health care insurance. ${ }^{[5]}$ As millions of the uninsured obtained insurance coverage, either through third parties or through the government marketplace (a website where people can find information about health insurance options and also purchase health care insurance), the demand for primary care providers increased. With a national physician shortage in primary care, Physician Assistants (PAs), have filled this gap with an increase of over 8,000 PAs working in primary care (Family and General practice / Internal Medicine Gen- eral practice) between 2014 and 2017. ${ }^{[6]}$ PAs are midlevel providers that were introduced in the US in the 1960s in response to a nationwide shortage of doctors in primary care and to increase the access to health care for people in underserved areas. PAs are health professionals with at least a master's level of education, who work with a supervising physician and are found in almost every medical and surgical specialty. Similar to their physician partners, PAs perform examinations, diagnosis, diagnostic testing, treatment, and prescribing. Over the last decade countries such as Canada, Netherlands, Australia, Germany and the UK have started to see small numbers of PAs in their health care workforce. ${ }^{[7]}$

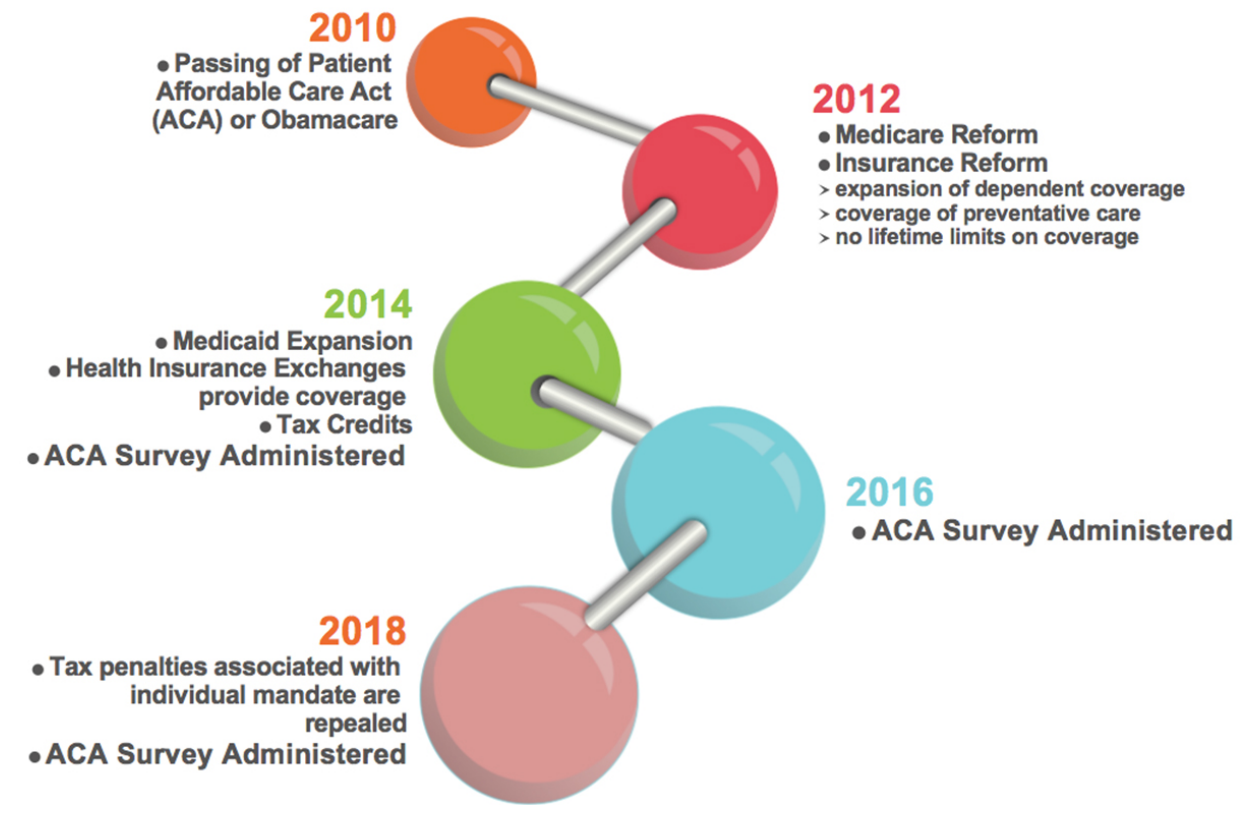

Figure 1. Timeline of implementation of the ACA and distribution of the survey to PAs

The ACA also supports innovative medical care delivery methods. Such approaches are the Accountable Care Organizations (ACOs) and the patient-centered medical homes. ACOs are groups of providers and organizations who come together voluntarily to give coordinated care to Medicare patients they serve. ${ }^{[8]}$ ACOs are built upon a team-based approach, which is a perfect fit for the PA whose profession is rooted in a team-based care approach. Based on this model, physician assistants have increasingly become an integral part of ACOs, as well as patient-centered medical homes. ${ }^{[9]}$

The influx of Americans with health insurance and the increased need for primary care providers, has fueled the change in the PAs "Scope of Practice" in many states. These changes are reflected in the change of PA practice from a required supervision by a physician to practice with collaboration of a physician. In many states these changes have increased the autonomy of practice for the PA. ${ }^{[10-12]}$

Although the literature has identified the role of the PA in meeting the needs of the newly insured Americans, there are few studies that have looked at the perception of the ACA by the physician assistants practicing after implementation of the ACA. ${ }^{[13-15]}$ The increased demand for midlevel providers as a result of the implementation of the ACA, is likely to have an impact on clinical practice as it relates to workload, patient demographics, and compensation of PAs. This study identifies how PAs perceive changes in health care over a four-year time (2014-2018) frame after implementation of the ACA. 


\section{Methods}

\subsection{Study design}

In this repeated cross-sectional study, PA alumni from a Midwest physician assistant program were surveyed on their knowledge and perception of the ongoing healthcare reform and the ACA in particular. Specifically, the questions addressed the impact of the ACA on healthcare, including patients' access to healthcare, changes in delivery and cost of healthcare as well as the influence of the ACA on their own practice. Participants were able to rank their respective responses on 22 specific questions/items.

\subsection{Tools and data collection}

Prior to instituting this study, approval by the institution's human subject review board was obtained (\#587601-1). The authors, following a thorough review of the literature, developed the survey tool to analyze the perception of PAs regarding the ACA. This tool incorporated the review of several similar surveys conducted by leading health care providers and insurance companies, assessing the perspectives of physicians as it relates to the affordable care act. ${ }^{[16-19]}$ Upon completion of the survey tool, feedback on overall survey coherence, balance and content was received from the university's experts in the statistics department. The tool consists of 22 questions, allowing a selection of multiple responses graded on a Likert scale. In addition, demographic questions related to area of practice and personal characteristics (i.e., gender) were asked. A fully completed questionnaire includes over 86 data points, with total aggregate data points accounting for close to 5,000, in addition to qualitative data. The questionnaire assesses the knowledge and perspective of PAs about the ongoing health care reform and its perceived impact on their practice (survey available upon request).

We divided a subset of the Survey questions into three categories based on three identified themes: 1) Perception of the ACA and impact on Health Care in the US by PAs (such as general knowledge about the ACA); 2) Perception of the impact of ACA on clinical practice (such as impact of the ACA on autonomy in practice) and 3) Perception of the impact of ACA on patient care (such as impact of the ACA on patient access to healthcare). A list of questions within each category is identified in Table 1.

Table 1. Categories of themes in the survey

\begin{tabular}{|c|c|c|}
\hline $\begin{array}{l}\text { Questions related to general perception of the } \\
\text { ACA and the impact on US Health Care }\end{array}$ & $\begin{array}{l}\text { Question related to impact of the ACA on } \\
\text { clinical practice }\end{array}$ & $\begin{array}{l}\text { Questions related to impact } \\
\text { of the ACA on patient care }\end{array}$ \\
\hline $\begin{array}{l}\text { - How knowledgeable are you about the } \\
\text { Affordable Care Act (ACA)? } \\
\text { - The ACA will improve health care in the US, } \\
\text { however further reforms are needed } \\
\text { - How do you feel about the future of healthcare } \\
\text { in the US? }\end{array}$ & $\begin{array}{l}\text { - Overall impact of ACA on your practice? } \\
\text { - Overall impact of ACA on your autonomy } \\
\text { in practice? } \\
\text { - Overall impact of ACA on compensation } \\
\text { for healthcare providers? } \\
\text { - Overall impact of ACA on your earnings? } \\
\text { - Is the ACA going increase the number of } \\
\text { patients in individual practices? }\end{array}$ & $\begin{array}{l}\text { - Is the ACA going to } \\
\text { increase access of patients } \\
\text { to healthcare? } \\
\text { - Is the ACA going to affect } \\
\text { patient's ability to choose } \\
\text { healthcare provider? }\end{array}$ \\
\hline
\end{tabular}

\subsection{Procedure}

The survey was sent in an e-mail to PA alumni that have graduated between the years of 1998 and 2013 from the PA program. The e-mail addresses were obtained from the University's alumni association, who keep a record of alumni contact information. Between the years of 1998 and 2018 there was a total of 425 alumni; contact information was available for 293 of the 425 alumni (69\%), to which the survey was sent. The e-mail contained a short description of the study and a link to the survey in SurveyMonkey ${ }^{\circledR}$, an online survey tool that allows for anonymity of responses. Consent was given by participants choice to participate in the survey. Of the 293 alumni contacted, 20 (6.8\%), 14 (4.8\%)

Published by Sciedu Press and 9 (3\%) completed the survey in 2014, 2016 and 2018 respectively, and were included in this study (see Table 2).

\subsection{Data analysis}

Questionnaire results were analyzed to provide summary descriptive statistics. SPSS version 20 (IBM, 2013) was used to perform the statistical analysis. Percentages of responses by PAs to each of the questions were calculated in SPSS and graphed using Microsoft word. Percent change and trends were analyzed. No statistical corrections such as weighting were used, but non-responders to individual questions were excluded from the analysis of those questions. 
Table 2. Demographic characteristics of survey respondents

\begin{tabular}{llll}
\hline Item & $\mathbf{2 0 1 4}$ & $\mathbf{2 0 1 6}$ & $\mathbf{2 0 1 8}$ \\
\hline Gender & & & \\
$\quad$ Male & $6(30 \%)$ & $4(29 \%)$ & $1(11 \%)$ \\
$\quad \begin{array}{l}\text { Female } \\
\text { Practice Location }\end{array}$ & $14(70 \%)$ & $10(71 \%)$ & $8(89 \%)$ \\
$\quad \begin{array}{l}\text { Michigan } \\
\quad \text { Other }\end{array}$ & 0 & 0 & $3(100 \%)$ \\
$\begin{array}{l}\text { Current Practice } \\
\quad \text { Primary care }\end{array}$ & $18(100 \%)$ & $6(67 \%)$ \\
$\quad$ Specialty field & $9(45 \%)$ & $9(64 \%)$ & $4(50 \%)$ \\
\hline
\end{tabular}

Note. ${ }^{*}$ PAs were asked if they had experience in working in a variety of health care fields which were subsequently grouped into primary care fields and specialty fields. Participants were asked if they currently worked or had worked in a list of medical practice fields and were allowed to choose more than one option if they had practiced in more than one field.

\section{RESULTS}

\subsection{Demographic characteristics}

Of the potential 425 GVSU PA alumni contacted, a combined $43(14.7 \%)$ responses to the survey at the three time points (20 in 2014, 14 in 2016 and 9 in 2018) were received. Most of the PAs that responded to the survey have been practicing between one and 14 years, predominantly in the State of Michigan (2014 and 2016 all respondents indicated that they practice in Michigan, while in 2018,33\% of the respondents indicated that they practice outside of Michigan). The PAs that responded to the survey in 2014, 2016 and 2018 practice in a wide range of practice settings, including family practice, pediatrics, internal medicine, cardiology, surgery and dermatology with a majority of respondents for each year of survey distribution having worked or are currently working in a primary care field (see Table 2). It should be noted that individuals could choose more than one type of practice if they had worked or are currently working in a different type of practice.

\subsection{PAs perception of the ACA and its impact on health care in the US}

A majority (89\%-100\%) of PAs that responded to the survey between 2014 and 2018 said that they are somewhat to very knowledgeable about the ACA (95\% in 2014; 100\% in 2016; and $89 \%$ in 2018). At the onset of the ACA in 2014, $45 \%$ of PAs felt that the ACA will improve healthcare, but further reforms are needed. This percentage increased to $57 \%$ in 2016 and $78 \%$ in 2018, as PAs continued to practice with the ACA in place. Concurrently, PAs continued to feel more positive about the future of healthcare in the US, with $35 \%$ feeling positive/somewhat positive in 2014, a number that rose to 58\% in 2016 and $67 \%$ in 2018 (see Table 3).

\subsection{PAs perception of influence of ACA on their practice}

Over the four years analyzed, the percentage of PAs that indicated that the ACA will have a positive impact on their practice increased from 30\% in 2014 to $67 \%$ in 2018 with the greatest increase between 2016 and 2018 (see Table 4). Similar to the improved perception of the impact of the ACA on their practice over the time period analyzed, PAs indicated that the ACA will have a positive impact on their autonomy in practice. In 2014, only $15 \%$ of PAs responded that the ACA will improve their autonomy in practice, which increased to $21 \%$ in 2016 and $45 \%$ in 2018. In 2014, the first year when most of the provisions included in the ACA took effect, $70 \%$ of PAs anticipated a decrease in compensation for health care providers and $60 \%$ of PAs predicted that the ACA will have a negative impact on their earnings. In 2018, four years after the implementation of the ACA, the number of PAs that expect an overall decrease in compensation for health care providers, and PAs in particular, has dropped from $70 \%$ in 2014 to $22 \%$. With implementation of the ACA in 2014, most PAs were convinced that the number of patients in individual practices will increase (95\%). Four years later, a majority of PAs still feel that way, although a slight decrease from $95 \%$ in 2014 to $86 \%$ in 2016 and $78 \%$ in 2018 is observed.

\subsection{Perception on the positive impact of the ACA on Pa- tients}

The PAs surveyed responded to statements regarding the impact of the ACA on their patients. Shortly after implementation of the major components of the ACA in 2014, PAs responded that $25 \%$ of the patients they cared for would be positively impacted by the ACA. The perception of a positive impact increased to 50\% in 2016 and 89\% in 2018 (see Table 5). This change over time reflects a dramatic increase in the positive impact of the ACA the PAs perceived for their patients. The response to the positive impact on their patients is mirrored by the responses obtained over time to the increased access to health care. In 2014, $45 \%$ of the PAs responded that the ACA would improve access of healthcare to patients, increasing to $78 \%$ in 2018 . Despite the perception of the increase in positive impact of the ACA on their patients, the PAs responded that the ACA would affect their patients' ability to choose a health care provider. In 2014, $60 \%$ responded that the ACA would affect the ability of their patients to choose a health care provider which rose to $78 \%$ in 2018. 
Table 3. Physician assistant knowledge of the ACA and perception of healthcare under the ACA

\begin{tabular}{llll}
\hline Item & $\mathbf{2 0 1 4}(\mathbf{N}=\mathbf{2 0})$ & $\mathbf{2 0 1 6}(\mathbf{N}=\mathbf{1 4})$ & $\mathbf{2 0 1 8}(\mathbf{N}=\mathbf{9})$ \\
\hline Very knowledgeable to somewhat knowledgeable about the ACA & $95 \%$ & $100 \%$ & $89 \%$ \\
ACA will improve healthcare in the US, however further reforms are needed & $45 \%$ & $57 \%$ & $78 \%$ \\
Positive/somewhat positive outlook of the future of healthcare in the US & $35 \%$ & $58 \%$ & $67 \%$ \\
\hline
\end{tabular}

Table 4. Physician assistant perception on the impact of the ACA on clinical practice

\begin{tabular}{llll}
\hline Item & $\mathbf{2 0 1 4}(\mathbf{N}=\mathbf{2 0})$ & $\mathbf{2 0 1 6}(\mathbf{N}=\mathbf{1 4})$ & $\mathbf{2 0 1 8}(\mathbf{N}=\mathbf{9})$ \\
\hline ACA will have a positive impact on PAs practice & $30 \%$ & $29 \%$ & $67 \%$ \\
ACA will have a positive impact on PAs autonomy in practice & $15 \%$ & $21 \%$ & $45 \%$ \\
ACA will have decrease compensation for health care providers & $70 \%$ & $64 \%$ & $22 \%$ \\
ACA will have a negative impact on PAs earnings & $60 \%$ & $43 \%$ & $22 \%$ \\
ACA will increase the number of patients in individual practices & $95 \%$ & $86 \%$ & $78 \%$ \\
\hline
\end{tabular}

Table 5. Physician assistant perception on the impact of the ACA on patient care

\begin{tabular}{llll}
\hline Item & $\mathbf{2 0 1 4}(\mathbf{N}=\mathbf{2 0})$ & $\mathbf{2 0 1 6}(\mathbf{N}=\mathbf{1 4})$ & $\mathbf{2 0 1 8}(\mathbf{N}=\mathbf{9})$ \\
\hline ACA will have a positive impact on their patients & $25 \%$ & $50 \%$ & $89 \%$ \\
ACA will increase access of patients to health care & $45 \%$ & $79 \%$ & $78 \%$ \\
ACA will affect patient's ability to choose a health care provider & $60 \%$ & $64 \%$ & $78 \%$ \\
\hline
\end{tabular}

\section{Discussion}

Our findings suggest that with integration of the ACA into the US health care system, PAs have developed a largely positive perspective of the ACA's impact on their practice as well as the patients they care for. Most of the PAs that responded had at least some knowledge about the ACA, allowing them to evaluate the influence of ACA specific components on their practice.

Importantly, this positive perspective translates into an optimistic outlook of the future of health care in the US by PAs, with those feeling positive or somewhat positive rising from $35 \%$ in 2014 to $67 \%$ in 2018 . Concurrently, the percentage of PAs that had a negative or somewhat negative outlook of the future of health care dropped from $40 \%$ in 2014 to $21 \%$ in 2016 and $11 \%$ in 2018 (data not shown). This is in contrast to $54 \%$ of physicians, who reported in a 2016 survey by the Physician Foundation that their morale was somewhat or very negative. ${ }^{[20]}$ Significantly, $62.8 \%$ of physicians reported that they are pessimistic about the future of the medical profession. One of the main reasons that physicians' state for their increased dissatisfaction is the loss of clinical autonomy. ${ }^{[20]}$ In contrast, PAs responding to our survey felt that over the past four years the ACA had an increasingly positive impact on their autonomy in practice, increasing from $30 \%$ in 2014 to $67 \%$ in 2018.

The passage of the ACA has affected the PA profession in several ways. With millions of uninsured Americans obtaining coverage, many for the first time, the demand for PAs has increased dramatically in recent years. ${ }^{[21]}$ This has led to a substantial expansion in the number of PAs, with a predicted increase in the need for PAs of $37 \%$ between 2016 and 2026. ${ }^{[22]}$ In addition, PAs are now enjoying widespread recognition as important members of the health care team by both the medical profession as well as U.S. patients, who are more and more comfortable being treated by someone other than a physician. ${ }^{[15]}$ With that, an unprecedented number of regulatory hurdles have been falling for PAs, leading to positive changes in their scope of practice as well as increased autonomy. Examples include the physician PA relationship, now in many states (including Michigan) referred to as a "collaborative practice" relationship rather than a "supervising physician" relationship. In addition, PAs are now able to independently prescribe controlled substances and some states adjusted the allowable reimbursement rate to match that of physicians. ${ }^{[10-12,23]}$ Our data reflects this increase in autonomy for the PA profession.

One of the goals of the ACA was to slow the rising cost of health care and to encourage a more efficient and higherquality health care system. This has led to a push to reform provider payment by gradually decreasing fee-for-service payments and replace them with new payment methodologies based on outcomes, such as bundled payments, patient centered medical homes and shared savings in ACO. ${ }^{[24,25]}$ The uncertainty about provider payment when most of the provisions of the ACA took into effect in 2014 likely contributed to PAs responding that the ACA will decrease compensation for health care providers, including PAs (see Table 4). Over the subsequent four years (2014 to 2018), the expec- 
tation of a negative impact of the ACA on compensation for health care providers lessened (from $70 \%$ in 2014 to $22 \%$ in 2016). This may be in part due to an actual gain in provider reimbursement as the number of patients with health care plans increased under the ACA. The ACA requires insurers to cover preventative services and essential health benefits such as maternity care, mental health services, medication, rehabilitation services and chronic disease management without an out-of-pocket payment form the patient. Providers in primary care and family practice, areas of medicine that cover many of these services and employ more than $25 \%$ of all PAs, ${ }^{[6,26]}$ benefited from these changes. ${ }^{[24,25]}$ Furthermore, an increased demand for PAs in the past four years has translated into an increase in the average salary for PAs, from $\$ 98,387$ in $2014^{[25]}$ to $\$ 103,921$ in $2018 .^{[28]}$

In addition to the increase in autonomy, and reimbursement over the last 4 years, the PAs surveyed have also felt the added influx of patients into the healthcare system at a time of workforce shortage. The American health care infrastructure has had a workforce shortage for decades, with the aging of the U.S. population and implementation of the ACA resulting in an even sharper increase in the demand. The Association of American Medical Colleges (AAMC) predicted a shortfall of up to 100,000 physicians by 2030 in the United States. ${ }^{[29]}$ Significant concern was raised by providers that the influx of newly insured patients would be too much to handle. These worries were underscored by predictions that the number of new visits to primary care physicians after implementation of the ACA would rise on average by $3.8 \%$ or 70 additional visits per physician per year. ${ }^{[30]}$ This concern was echoed by PAs responding to the survey, with $95 \%$ of PAs expecting in 2014 that the number of patients in individual practices would increase. This number dropped slightly over the next four years, to $86 \%$ in 2016 and $78 \%$ in 2018; however, with more patients accessing the healthcare services, most PAs responded that the workload continues to increase for health care providers (data not shown). Traditional as well as innovative solutions are being considered to ease the provider shortfall. These include an increase in training of future health care providers, specifically midlevel providers such as PAs and Nurse Practitioners (NP). Training for these professions is relatively short (on average two years of post-graduate education), making them more quickly available to the workforce. ${ }^{[31]}$ Although PAs and NPs have a more limited scope of practice, they have been proven to provide many types of care at a quality and satisfaction level similar to that of physicians. Other approaches include health information interoperability (such as Electronic Health Record-EHR), which provides real time access to patient information improving clinical efficiency of cross- disciplinary teams. Use of Telemedicine, such as remote patient monitoring (or homecare telehealth) is also an important new technology that improves patients access to care while reducing office visits and hospitalization. ${ }^{[30]}$

Even with the influx of patients into the healthcare system over the last four years, the PAs responded with a dramatic increase in the positive impact that the ACA has had on their patients over the past four years (see Table 5). In 2014, 25\% of the PAs surveyed responded that the ACA will have a positive impact on their patients which increased to $89 \%$ in 2018. The positive impact on patients was also reflected in the PAs response to an increase in access of patients to healthcare which rose from $45 \%$ in 2014 to $78 \%$ in 2018 . Increase in access to healthcare has received a great deal of attention in the literature. Most literature has cited increased access to healthcare while others have identified pockets of society that continue to have disparities. ${ }^{[32-36]}$ Using the Behavioral Risk Factor Surveillance System (BRFSS), Courtemanche et al. ${ }^{[32]}$ found that the ACA led to large gains in all access measures: insurance coverage increased $(8.3 \%)$, probability of having a primary care doctor increased $(3.1 \%)$, probability of cost being a barrier to care declined $(5.1 \%)$, and probability of having a checkup increased (3.6\%). Simon et al. ${ }^{[34]}$ also used the BRFSS to report an increase in access to healthcare after implementation of the ACA. Using two primary data points (whether the subject has a primary care physician, and whether the subject in the past 12 months needed to see a doctor but could not because of cost) Simon found that the Medicaid expansion increased access to healthcare in the pooled sample, women, and childless adults, with the greatest impact on childless adults. Miller and Wherry ${ }^{[33]}$ also found significant improvement in access to care along multiple parameters during the second year of ACA implementation utilizing data from the National Health Interview Survey (Ex. needing to see a specialist, needing medical care). Other factors increasing the access to healthcare have been the establishment of innovative medical care delivery methods. Saloner et al. ${ }^{[37]}$ also reported that community health centers (supported by the ACA's approach to innovative medical care delivery) were utilized significantly more in 2016 compared to 2012/2013 and that there was increased availability of appointments without increased wait times. Our data support the positive impact of the ACA on patients.

Over the time span of four years, we saw an increase in the percentage of PAs that perceived the ACA will affect their patients' ability to choose their provider. This ability of patients to choose their provider after implementation of the ACA has received criticism along the political front. Prior to the ACA, many individuals had insurance plans such as PPO's which allowed them to choose their provider and health care insti- 
tution. After implementation of the ACA, the government marketplace created narrow network plans as a cost containing strategy. ${ }^{[38,39]}$ The narrow network plans eliminated providers within the plan making it difficult for the patient to keep their original provider. Keeping their original physician was possible but if the provider was not within the narrow network, patients are now required to pay out-of-network prices. In 2018, a report identified that network plans are becoming more managed leading to less consumer choice. ${ }^{[38]}$ In addition, because of the increase in individuals obtaining health insurance there has been a three-fold increase in individuals who receive care through a narrowed network. Our findings support the increase in narrow-networks through the perception by PAs that the ACA is affecting their patients' choice of health care provider.

The findings of this study highlight that over the past four years, practicing PAs adjusted their perception about the impact of the ACA as it relates to their practice, income, autonomy, as well as the effect the ACA has on their patients. It is likely that these changes in perception resulted from a greater understanding of the ACA's impact on PA practice over the time period studied. With the ACA remaining a viable entity in the health care delivery system in the United States, these results suggest that an introduction to the ACA, and specifically its impact on PA practice, during PA training would be beneficial. Through educational instruction PA students can learn about the general impact of the ACA on PA practice, and will be less likely swayed by the media portrayal of the delivery of healthcare under the ACA.

Although this study does identify similar findings in the literature, there were multiple limitations affecting the generalizability of the results. The study population is derived from alumni from one PA program, whose graduates are largely practicing in the state of Michigan. This limits the responses and perceptions to the questions as some aspects of the ACA differ from state to state, most notably Medicaid expansion and health plan availability and cost. The sample size decreased with each subsequent distribution of the survey lending the data difficult to observe statistical significance over time. In addition, there was a decrease in the number of individuals who worked in primary care over the years surveyed.

\section{Conclusion}

Implementation of the ACA in 2014 created apprehension in not only patients but also in health care providers who questioned the impact of the ACA on their practice, as well as questioned the impact on their patients. This study identified that during the first year of implementation, physician assistants had concern over the future of health care, as well as their personal compensation and autonomy. These factors became less of a concern four years later. Four years after implementation of the ACA a majority of the surveyed physician assistants had a more positive perspective on healthcare and the impact of the ACA on their practice, including practice autonomy and compensation. In addition, literature has identified that since implementation of the ACA, physician assistant salary, autonomy, and employment have all increased which support the change in perception of physician assistants over the past four years. As implementation of the ACA evolves, further studies are warranted to identify effects on professional practice, as well as to provide insight into those changes by the professionals who are at ground level implementing the changes.

\section{CONFlicts OF INTEREST Disclosure}

The authors declare no conflicts of interest.

\section{REFERENCES}

[1] Centers for Medicare \& Medicaid Services. National Health Expenditure (NHE) Data Fact Sheet: Projected NHE, 2017-2026. [Internet] 2018. Available from: https://www.cms.gov/research-stati stics-data-and-systems/statistics-trends-and-repor ts/nationalheal thexpenddata/nhe-fact-sheet.html

[2] Obama B. United States Health Care Reform: Progress to Date and Next Steps. JAMA. 2016; 316(5): 525-32. PMid:27400401. https://doi.org/10.1001/jama. 2016.9797

[3] Hellerstedt W. The Affordable Care Act: What Are Its's Goals and Do We Need It? 2013 September [cited 2019 March 4]. The Center for Leadership Education Public Health, University of Minnesota; [Internet]. Available from: http://www. epi .umn.edu/mch/wp-c ontent/uploads/2013/09/ACA-Overview.pdf

[4] Norris L. Will the IRS still enforce the individual mandate

Published by Sciedu Press penalty for 2018 tax returns? 2018 December [cited 2019 March 24]. Health Insurance.org; [Internet]. Available from: https://www.healthinsurance.org/faqs/does-the-pre sidents-executive-order-mean-the-irs-wont-enforce -the-individual-mandate-penalty/

[5] Bakalar N. Nearly 20 Million Have Gained Health Insurance Since 2010. The New York Times; [Internet]. 2017, May 22. Available from: https://www.nytimes.com/2017/05/22/health/obam acare-health-insurance-numbers-nchs.html

[6] National Commission on Certification of Physician Assistants, Inc. 2017 Statistical Profile of Certified Physician Assistants: An Annual Report of the National Commission on Certification of Physician Assistants. [Internet] 2018 May. Available from: http://www.nc cpa.net/research

[7] Halter M, Drennan V, Chattopadhyay K, et al. The Contribution 
of physician assistants in primary care: a systematic review. BMC Health Serv Res. 2013; 13: 223. PMid:23773235. https ://doi.or $\mathrm{g} / 10.1186 / 1472-6963-13-223$

[8] Abrams MK, Nuzum R, Zezza MA, et al. The Affordable Care Act's Payment and Delivery System Reforms: A Progress Report at Five Years. The Commonwealth Fund [Internet]. 2015 May [cited 2019 Jan 7]. Available from: https://www. commonwealthfund.org /publications/issue-briefs/2015/may/affordable-car e-acts-payment-and-delivery-system-reforms

[9] Meyers D, Peikes D, Genevro J, et al. The Roles of PatientCentered Medical Homes and Accountable Care Organizations in Coordinating Patient Care. Agency for Healthcare Research and Quality Publication No. 11-M005-EF. [Internet]. 2010 December [cited 2019 Jan 15]. Available from https://healthit.ahrq.gov/ahrq-funded-projects/es tablishing-federal-resources-support-patient-cente red-medical-home-concept/citation/roles

[10] Bosler B, Reed K. A New Scope of Practice for PAs and APRNs in Michigan. State Bar of Michigan Health Care Law Section [Internet]; 2018. Available from: https://www.dykema.com/media/publication/166_New_R oles_for_PAs_and_APRNs_in_Michigan_-_July_2018.pdf

[11] Larson J. The Future of Physician Assistant Practice Authority. 2018 May [cited 2019 Jan 7]. Staff Care [Internet]. Available from: https://www.staffcare.com/physician-blogs/the-fut ure-of-physician-assistant-practice-authority-sop/

[12] Japsen B. States Lift More Hurdles to Physician Assistants. Forbes [Internet] 2017, September 8. Available from: https://www . aapa.org/news-central/2017/09/states-1 ift-hurdles-physician-assistants/

[13] Hooker RS, Everett CM. The contributions of physician assistants in primary care systems. Health \& Social Care in the Community. 2011; 20(1): 20-31. PMid:21851446. https://doi.org/10.111 $1 / j .1365-2524.2011 .01021 . x$

[14] United Health Group: Primary Care Report. Addressing the Nation's Primary Care Shortage: Advanced Practice Clinicians and Innovative Care Delivery Models. [Internet] 2018 September. Available from: https://www. unitedhealthgroup.com/content/dam/ UHG/PDF/2018/UHG-Primary-Care-Report-2018.pdf

[15] Sanborn BJ. While PCP office visits decline, stats for NPs and PAs are way up showing promise for bridging future care gaps. [Internet] Health Care Finance; 2018 September [cited 2019 Jan 7] Available from: https://www.healthcaref inancenews.com/news/whi le-pcp-office-visits-decline-stats-lpns-and-pas-a re-way-showing-promise-bridging-future-care

[16] Jackson Healthcare: Advanced Practice Trends 20122013. An Attitude \& Outlook Report On Nurse Practitioners \& Physician Assistants. [Internet] Available from: https://jacksonhealthcare.com/media-room/surveys/ advanced-practice-trends-2012-2013/

[17] Jackson \& Coker. Survey: Physicians on the Affordable Care Act. [Internet] 2013. Available from: https://jacksoncoker.com/m edia/1254/physician-survey-obamacare.pdf

[18] Wolters Kluwer Health. Wolters Kluwer Health 2013 Physician Outlook Survey. [Internet] 2013. Available from: https: //wolterskluwer.com/binaries/content/assets/wk-hea lth/pdf/company/newsroom/white-papers/wolters-klu wer-health-physician-study-executive-summary.pdf

[19] The Physicians Foundation. A Survey of America's Physicians: Practice Patterns and Perspectives. [Internet] 2012. Available from: https://physiciansfoundation.org/focus-areas/a-sur vey-of-americas-physicians-practice-patterns-and-p erspectives/

[20] The Physicians Foundation. A Survey of America's Physicians: Practice Patterns and Perspectives. [Internet] 2016. Available from: https://physiciansfoundation.org/wp-content/u ploads/2018/01/Biennial_Physician_Survey_2016.pdf

[21] Bureau of Labor Statistics, U.S. Department of Labor, Occupational Outlook Handbook, Physician Assistants. [cited 2019 March 26]. Available from: https://www.bls.gov/ooh/healthcare/phy sician-assistants.htm

[22] United States Department of Labor-Bureau of Labor Statistics. Occupational Outlook Handbook: Physician Assistants. [Internet] 2018 April. Available from: https://www.bls.gov/ooh/healthcare /physician-assistants.htm

[23] Scope of Practice Policy. Physician Assistants and Collaboration. [Internet] 2017 June. Available from: http://scopeofpracticepolicy.org/physician-ass istants/physician-assistants-collaboration/

[24] Bowling B, Newman D, White C, et al. Provider reimbursement following the Affordable Care Act. Health Care Manag (Frederick) 2018; 37(2): 129-135. https://doi.org/10.1097/HCM. 000000 0000000205

[25] Page L. 8 Ways That the ACA Is Affecting Doctors' Incomes.[Internet] NEJM Career Center 2013 [cited 2019 Jan7] Available from: https://www.nejmcareercenter.org/minis ites/rpt/8-ways-that-the-aca-is-affecting-doctors -incomes/

[26] WellPoint. WellPoint launches innovative reimbursement initiative, partnering with primary care to improve quality and reduce medical costs. [Press release] [Internet] 2012 Jan 27 [cited 2019 Jan11]. Available from: https: //ir.antheminc.com/news-releases/news-release-det ails/wellpoint-launches-innovative-reimbursement-i nitiative?field_nir_news_date_value [min] $=2019$

[27] National Commission on Certification of Physician Assistants, Inc. 2014 Statistical Profile of Certified Physician Assistants: An Annual Report of the National Commission on the Certification of Physician Assistants. [Internet] 2015 March. Available from: http: //www.nccpa.net/research. Accessed January 7, 2019.

[28] Physician Assistant - Medical in the United States. [Internet] Salary.com [cited 2019 Jan 7]. Available from: https://www1. sal ary.com/Physician-Assistant-Medical-Salary.html

[29] Flier J. How can we remedy the shortage of health providers? [Internet] STAT; 2018 Feb 21 [cited 2019 Jan 7]. Available from: https://www. statnews . com/2018/02/21/health-pro viders-shortage/

[30] Edlund T. How the Affordable Care Act is Affecting Physician Workloads. [Internet] Softworks Group; 2015 March 10 [cited 2019 Jan 7] Available from: https: //www . softworksgroup.com/synoptec-blog/how-the-aff ordable-care-act-is-affecting-physician-workloads/

[31] Rosenfeld J. Different Solutions for the Physician Shortage. [Internet] Modern Medicine Network; 2017 Oct 23 [cited 2019 Jan7]. Available from: http://www . physicianspractice.com/diffe rent-solutions-physician-shortage

[32] Courtemanche C, Marton J, Ukert B, et al. Effects of the Affordable Care Act on Health Care Access and Self-Assessed Health After 3 Years. Inquiry. 2018; 55. https ://doi .org/10.1177/00469580 18796361

[33] Miller S, Wherry LR. Health and Access to Care during the First 2 Years of the ACA Medication Expansions. N Engl J Med. 2017; 376: 
947-956. PMid:28273021. https://doi.org/10.1056/NEJMsa 1612890

[34] Simon K, Aparna S, Cawley J. The Impact of Health Insurance on Preventive Care and Health Behaviors: Evidence from the First Two Years of the ACA Medicaid Expansions. Journal of Policy Analysis and Management. 2017; 36(2): 390-417. PMid:28378959. https://doi.org/10.1002/pam. 21972

[35] Sommers BD, Gunja MZ, Finegold K, et al. Changes in self-reported insurance coverage, access to care, and health under the Affordable Care Act. JAMA. 2015; 314(4): 366-374. PMid:26219054. https://doi.org/10.1001/jama.2015.8421

[36] Wherry LR, Miller S. Early Coverage, Access, Utilization, and Health Effects Associated with the Affordable Care Act Medicaid Expansions: A Quasi-experimental Study. Annals of Internal Medicine. 2016; 164(12): 795-803. PMid:27088438. https: //doi.org/10.7326/M15-2234
[37] Saloner B, Wilk AS, Wissoker D, et al. Changes in primary care access at community health centers between 2012/2013 and 2016 . Health Serv Res. 2018; Nov 5. PMid:30397918.

[38] McKinsey Center for U.S. Health System Reform. Hospital networks: perspective from three years of exchanges [Internet]. New York (NY): McKinsey and Company; 2016 Mar 5 [Cited 2019 January 8]. Available from: https://healthcare.mckinsey.com/sites/ default/files/McKinsey\%20Reform\%20Center_2016\%20Ex change\%20Networks_FINAL.pdf

[39] Polsky D, Cidav Z, Swanson A. Market place plans with narrow physician networks feature lower monthly premiums than plans with larger networks. Health Aff (Millword). 2016; 35(10): 1842-8. PMid:27702958. https://doi.org/10.1377/hlthaff.2016.0 693 